TITLE:

\title{
Hydrogen atom formation from the photodissociation of water ice at $193 \mathrm{~nm}$
}

\section{AUTHOR(S):}

Yabushita, A; Hashikawa, Y; Ikeda, A; Kawasaki, M; Tachikawa, $\mathrm{H}$

\section{CITATION:}

Yabushita, A ... [et al]. Hydrogen atom formation from the photodissociation of water ice at 193 nm. JOURNAL OF CHEMICAL PHYSICS 2004, 120(11): 5463-5468

\section{ISSUE DATE:}

2004-03-15

URL:

http://hdl.handle.net/2433/39757

\section{RIGHT:}

Copyright 2004 American Institute of Physics. This article may be downloaded for personal use only. Any other use requires prior permission of the author and the American Institute of Physics. 


\title{
Hydrogen atom formation from the photodissociation of water ice at $193 \mathrm{~nm}$
}

\author{
Akihiro Yabushita, Yuichi Hashikawa, Atsushi Ikeda, and Masahiro Kawasaki \\ Department of Molecular Engineering, and Graduate School of Global Environmental Studies, \\ Kyoto University, Kyoto 615-8510, Japan \\ Hiroto Tachikawa \\ Department of Molecular Chemistry, Graduate School of Engineering, Hokkaido University, \\ Sapporo 060-8628, Japan
}

(Received 21 April 2003; accepted 27 August 2003)

\begin{abstract}
The TOF spectra of photofragment hydrogen atoms from the $193 \mathrm{~nm}$ photodissociation of amorphous ice at $90-140 \mathrm{~K}$ have been measured. The spectra consist of both a fast and a slow components that are characterized by average translational energies of $2 k_{B} T_{\text {trans }}=0.39 \pm 0.04 \mathrm{eV}$ $(2300 \pm 200 \mathrm{~K})$ and $0.02 \mathrm{eV}(120 \pm 20 \mathrm{~K})$, respectively. The incident laser power dependency of the hydrogen atom production suggests one-photon process. The electronic excitation energy of a branched cluster, $\left(\mathrm{H}_{2} \mathrm{O}\right)_{6+1}$, has been theoretically calculated, where $\left(\mathrm{H}_{2} \mathrm{O}\right)_{6+1}$ is a $\left(\mathrm{H}_{2} \mathrm{O}\right)_{6}$ cyclic cluster attached by a water molecule with the hydrogen bond. The photoabsorption of this branched cluster is expected to appear at around $200 \mathrm{~nm}$. The source of the hydrogen atoms is attributed to the photodissociation of the ice surface that is attached by water molecules with the hydrogen bond. Atmospheric implications are estimated for the photodissociation of the ice particles (Noctilucent clouds) at 190-230 nm in the region between 80 and $85 \mathrm{~km}$ altitude. (C) 2004 American Institute of
\end{abstract} Physics. [DOI: 10.1063/1.1619939]

\section{INTRODUCTION}

Experimental and theoretical studies on the photodissociation of water have been extensively reported because of its importance to reaction dynamics and kinetics, atmospheric chemistry, astrophysics, etc. ${ }^{1,2}$ A water molecule in the gas phase has the dissociation threshold of $5.1 \mathrm{eV}$ to $\mathrm{H}+\mathrm{OH}$, while it has the first absorption band in the vacuum ultraviolet region below $185 \mathrm{~nm}(6.7 \mathrm{eV})$ and its absorption cross section at around $200 \mathrm{~nm}(6.2 \mathrm{eV})$ is very small, $10^{-23} \mathrm{~cm}^{2} .^{3}$ The electronic transitions are of the Rydberg types. ${ }^{4}$ The vertical transition at $\sim 200 \mathrm{~nm}$ requires excitation far into the classically forbidden regions of the $\mathrm{OH}$ stretch potential, where the ground state wave function amplitude is rapidly decaying. ${ }^{5}$ In the condensed phase, due to the hydrogen-bonding among water molecules, the photoabsorption is blueshifted. The threshold for absorption spectra appears to be at $165 \mathrm{~nm}^{6,7}$ However, Dressler and Schnepp reported a region of weak and continuous absorption extending from 180 to $210 \mathrm{~nm}$ with a shallow maximum near 195 $\mathrm{nm} .{ }^{8}$ The absorption spectrum of polycrystalline hexagonal ice at the very tail in the range from 180 to $194 \mathrm{~nm}$ was measured at $263 \mathrm{~K}$ by Minton. ${ }^{9}$ Since the intensity of this red-tailed band does not measurably increase with the water layer thickness, it may be relevant to surface water molecules and not to a cooled bulk ice. In this paper we have investigated the UV photodissociation dynamics of water ice at 193 and $248 \mathrm{~nm}$ with time-of-flight photofragment spectroscopy. Our purpose is to observe directly the formation of hydrogen atoms from the UV photodissociation of ice and estimate its influence on the mesosphere ozone depletion since there are appreciable amounts of small water-ice par- ticles including the noctilucent clouds in the high-latitude mesopause region where the solar radiation at $\sim 200 \mathrm{~nm}$ is stronger than at the Lyman- $\alpha$ line.

\section{AB INITIO THEORETICAL CALCULATIONS OF THE ELECTRONIC EXCITATION ENERGY OF A WATER MOLECULE ON A MODEL ICE SURFACE}

In the present calculation, the structural model of an ice surface is constructed of cyclic six water molecules $\left(\mathrm{H}_{2} \mathrm{O}\right)_{n}$ $(n=6)$, which is extracted from a structure of bulk ice. Its structure is fixed in the following calculations. Furthermore, one water molecule is connected by a hydrogen bond to the dangling $\mathrm{OH}$ group of the model water cluster. Here, this branched cluster is denoted by $\left(\mathrm{H}_{2} \mathrm{O}\right)_{6+1} \cdot{ }^{10}$ The position and structure of the added water molecule on the sixmembered water cluster $\left(\mathrm{H}_{2} \mathrm{O}\right)_{6}$ were fully optimized by means of the HF/6-311++ $\mathrm{G}(d, p)$ method. ${ }^{11}$ The optimized structure of $\left(\mathrm{H}_{2} \mathrm{O}\right)_{6+1}$ is illustrated in Fig. 1. The oxygenoxygen bond distance of the hydrogen bond was calculated to be $3.0967 \AA$. The water molecule is bound by the hydrogen bond $\left(4.6 \mathrm{kcal} \mathrm{mol}^{-1}\right)$. Using a grazing-angle Fourier transform infrared reflection absorption spectroscopy, Zondlo et al. monitored the free $\mathrm{OH}$ stretch (or "dangling bond") in vapor-deposited $\mathrm{H}_{2} \mathrm{O}$-ice films between 94 and $120 \mathrm{~K}^{12}$ The temperature and pressure dependence of the dangling bond signal during film growth was used to estimate $E_{\text {dif }}$ for $\mathrm{H}_{2} \mathrm{O}$ on amorphous ice. They measured an upper limit of $E_{\text {dif }}$ $=4.2 \pm 0.5 \mathrm{kcal} \mathrm{mol}^{-1}$, which is inconsistent with the bond energy for the water molecule on the model ice surface. For 


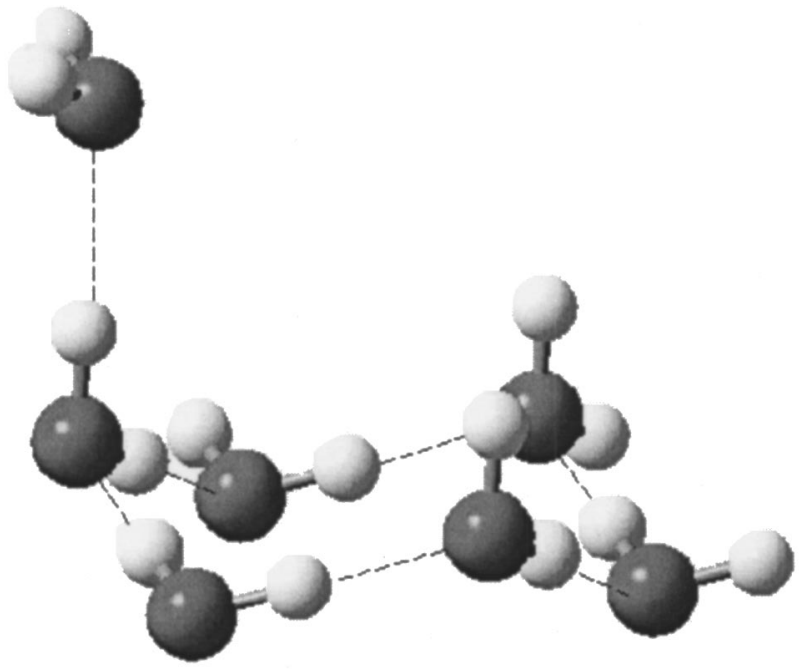

FIG. 1. Optimized structure of a water molecule that is hydrogen-bonding to a model crystalline surface consisting of $\left(\mathrm{H}_{2} \mathrm{O}\right)_{6}$. The $\left(\mathrm{H}_{2} \mathrm{O}\right)_{6+1}$ water cluster is optimized at the HF/6-311++G(d,p) level. Refer to Ref. 10 .

a vapor-deposited water molecule on an water ice surface, a theoretical value for a barrier to diffusion $\left(E_{\text {dif }}\right)$ was $E_{\text {dif }}$ $=2.5-3 \mathrm{kcal} \mathrm{mol}^{-1} .13$

The electronic excitation energies were calculated by means of the complete active space multiconfiguration selfconsistent field (CAS-SCF) method with a 6-311+ $+\mathrm{G}(d, p)$ basis set. ${ }^{14}$ Four electrons in four orbitals were considered as active electrons and active orbitals, respectively. At the CAS(4,4)/6-311++ G(d,p)//MP2/6-311+ $+\mathrm{G}(d, p)$ level, the first vertical excitation energy of $\left(\mathrm{H}_{2} \mathrm{O}\right)_{6+1}$ was calculated to be $6.62 \mathrm{eV}$, which is $0.11 \mathrm{eV}$ lower than that of free $\mathrm{H}_{2} \mathrm{O}(6.73 \mathrm{eV})$. The red shift is caused by an electron transfer from the hydrogen bond to the free (not hydrogen-bonded) hydrogen atom in the hydrogen-bond acceptor water molecule at the excited state. The charge of the hydrogen bonding $\mathrm{H}$ atom becomes partially positive, which is attracted by the negative charge of the oxygen atom of the hydrogen bond acceptor water molecule. Thus, the orbital energy is stabilized in the electronically excited state of the donor water molecule. As an additional test, we have calculated the first vertical excitation energies for water monomer, dimer, cyclic trimer, and cyclic tetramer: $6.73 \mathrm{eV}$ for $\mathrm{H}_{2} \mathrm{O}, 6.52 \mathrm{eV}$ for $\left(\mathrm{H}_{2} \mathrm{O}\right)_{2}, 7.05 \mathrm{eV}$ for $\left(\mathrm{H}_{2} \mathrm{O}\right)_{3}, 7.39 \mathrm{eV}$ for $\left(\mathrm{H}_{2} \mathrm{O}\right)_{4}$. Furthermore, based on our calculation, we have found that the branched clusters have always smaller excitation energies than the corresponding cyclic clusters: $6.55 \mathrm{eV}$ for $\left(\mathrm{H}_{2} \mathrm{O}\right)_{3+1}, 6.84 \mathrm{eV}$ for $\left(\mathrm{H}_{2} \mathrm{O}\right)_{4+1}$.

The cyclic trimer and tetramer have larger energies than the monomer. The dimer excitation energy is smaller than the monomer energy. This is in good agreement with the results reported by Harvey et al. ${ }^{15}$ who calculated absorption line shapes of water clusters, $\left(\mathrm{H}_{2} \mathrm{O}\right)_{n}, n=2-6$. Their calculated UV spectra of the cyclic water clusters $(n=3-6)$ indicate a strong blueshift with extended blue tails relative to the water monomer. Only in the case of the dimer, the absorption band appears at the red region. The redshifted absorption was attributed to the low excitation energy of the hydrogen-bond donor water molecule because of its high polarizability in the excited state. All other water cyclic clusters larger than trimer exhibited a blueshift in the ultraviolet absorption bands because each water molecule is equally considered as a donor as well as an acceptor. An additional red tail appears only in the case of the dimer absorption band. ${ }^{15}$ This red-tailed band arises from the hydrogen-bond donor $\mathrm{H}_{2} \mathrm{O}$ molecule due to the wings in the ground state vibrational wave function that extend into the valleys of the dissociative excited state potential.

The blueshifted absorption spectra of cyclic water clusters are relevant to the vacuum UV absorption of bulk ice. The red absorption tail of the dimer is relevant to that of the vapor-deposited amorphous ice surface that is attached by water molecules. Thus, the amorphous water ice surface can have optical and structural characters similar to the water dimer.

\section{EXPERIMENT}

The experiments were performed in an ultrahigh vacuum chamber equipped with a pulsed gas source, excimer laser, and dye laser. The vacuum chamber was evacuated by two turbomolecular pumps in tandem $\left(600\right.$ and $\left.50 \mathrm{~L} \mathrm{~s}^{-1}\right)$. The base pressure was $0.5 \times 10^{-8}$ Torr. A fused sapphire substrate was mounted on a liquid-nitrogen reservoir attached to a holder on an $X-Y-Z$ stage, and was heated by a tantalum filament $\left(0.35 \mathrm{~mm}\right.$ diam). The substrate temperature, $T_{\text {sub }}$, was controlled in the range $90-700 \mathrm{~K}$, which was maintained within $1 \mathrm{~K}$ and was monitored with an AlumelChromel resistance thermometer attached into the sapphire substrate. The substrate was cleaned by oxygen atoms produced from the $193 \mathrm{~nm}$ photodissociation of gaseous $\mathrm{NO}_{2}$ at $T_{\text {sub }}=520 \mathrm{~K}$ for $60 \mathrm{~min}$. This cleaning had no appreciable effect on the experimental results probably because the ice film thickness was more than a few hundred monolayers. However, when the probe laser light mistakenly hit the substrate surface, the experimental results were strongly affected probably because the growth of ice films were not uniform. The experimental details have been published elsewhere. ${ }^{16}$

A $\mathrm{H}_{2} \mathrm{O}$ (or $\mathrm{D}_{2} \mathrm{O}$ ) ice film was prepared by deposition of water vapor on the sapphire substrate at $T_{\text {sub }}=90 \mathrm{~K}$ with a pulsed gas head (General Valve, $10 \mathrm{~Hz}$ ). A typical stagnation pressure of neat water vapor was 20 Torr. The state of water ice films is the porous amorphous solid water, which was prepared with the background deposition of water vapor at $90 \mathrm{~K}$ for $60 \mathrm{~min}$, and then, annealed to the substrate temperature unless otherwise stated. The exposure was typically $1800 \mathrm{~L}\left(1 \mathrm{~L}=1 \times 10^{-6}\right.$ Torr s). This exposure resulted in formation of $600 \mathrm{ML}$ of $\mathrm{H}_{2} \mathrm{O}$ (or $\mathrm{D}_{2} \mathrm{O}$ ) on the substrate if we adopt the reported experimental conversion factor of $1 \mathrm{ML}$ deposition by $3 \mathrm{~L}$ exposure, ${ }^{17}$ which is in good agreement with $780 \mathrm{ML}$ calculated kinematically for hexagonal crystalline density $\left(1.1 \times 10^{15} \mathrm{~cm}^{-2}\right),{ }^{18}$ collision velocity for $300 \mathrm{~K}$ gas and the sticking coefficient of unity. ${ }^{19}$ The characteristics of the porous amorphous solid water are the existence of free $\mathrm{OH}$ groups and the porosity of the ice surface. ${ }^{20}$

Time-of-flight spectra of $\mathrm{H}$ (or D) atoms formed from the photodissociation of water ice were measured by the resonance-enhanced multiphoton ionization (REMPI) tech- 


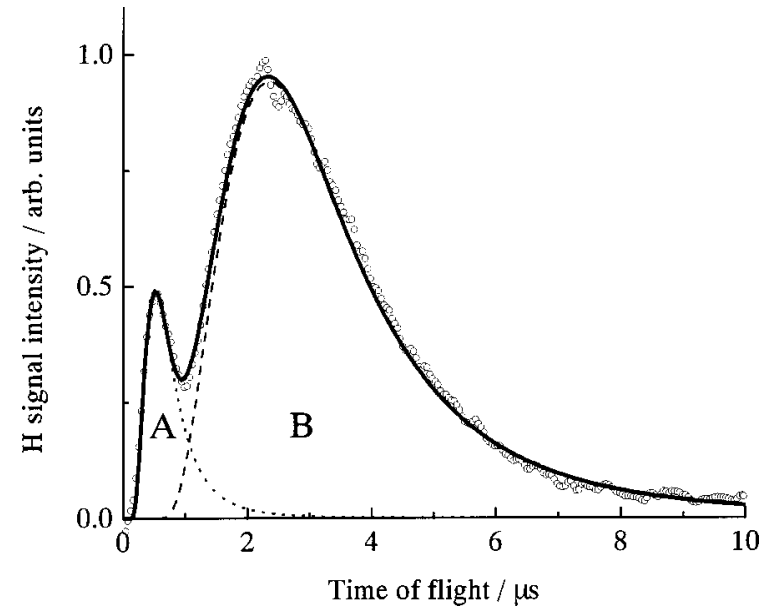

FIG. 2. A typical time-of-flight spectrum of $\mathrm{H}$ atoms from the $193 \mathrm{~nm}$ dissociation of amorphous ice at $90 \mathrm{~K}$. The dotted curve and the broken curve are simulated ones for the Maxwell-Boltzmann velocity distributions with $(A) T_{\text {trans }}=2300 \mathrm{~K}$ and $(B) T_{\text {trans }}=120 \mathrm{~K}$, respectively, using Eq. (1). This TOF spectrum is averaged over the entire Doppler profile of the REMPI spectrum of the $\mathrm{H}$ atom.

nique. A water ice film on the sapphire substrate $(12 \mathrm{~mm}$ diameter) was photodissociated at $193 \mathrm{~nm}$ with an ArF excimer laser (Lambda Physik, COMPex, $10 \mathrm{~Hz}$, typically reduced to $0.5 \mathrm{~mJ} \mathrm{~cm}^{-2}$ pulse $\mathrm{s}^{-1}$ by optical filters) and at 248 $\mathrm{nm}$ with a $\mathrm{KrF}$ excimer laser (typically $2 \mathrm{~mJ} \mathrm{~cm}^{-2}$ pulse $^{-1}$ ). Neutral hydrogen atom photofragments produced by the photolysis laser pulse were ionized through a $(2+1)$ REMPI process at $243.1 \mathrm{~nm}$ with an $\mathrm{Nd}^{3+}$ :YAG laser pumped dye laser (Lambda Physik, SCANmate, $0.2 \mathrm{~mJ} \mathrm{pulse}^{-1}$ at UV) with a lens $(f=0.20 \mathrm{~m})$. The subsequent REMPI signals of the atoms were detected by a homemade time-of-flight mass spectrometer. The distance between the substrate and the detection region was variable from 3 to $5 \mathrm{~mm}$. It was usually set to $3 \mathrm{~mm}$. TOF spectra were taken as a function of time delay, $t$, between the photolysis and probe laser pulses, which corresponds to the flight time between the substrate and the detection region.

\section{EXPERIMENTAL RESULTS AND DISCUSSION}

Figure 2 shows a typical TOF spectrum of $\mathrm{H}$ atoms from $\mathrm{H}_{2} \mathrm{O}$ ice films at $90 \mathrm{~K}$ and $193 \mathrm{~nm}$, which is a sum of the spectra measured at several Doppler shifts of the REMPI excitation spectrum. The TOF spectrum was fitted with $S\left(a, t, T_{1}, T_{2}\right)$, consisting of two flux weighted MaxwellBoltzmann distributions defined by the translational temperature $T_{i}$ and a coefficient, $a$,

$$
\begin{aligned}
& S\left(a, t, T_{1}, T_{2}\right)=a S_{\mathrm{MB}}\left(t, T_{1}\right)+(1-a) S_{\mathrm{MB}}\left(t, T_{2}\right), \\
& S_{\mathrm{MB}}(t, r)=r^{3} t^{-4} \exp \left[-m r^{2} /\left(2 k_{B} T_{\text {trans }} t^{2}\right)\right], \\
& P_{\mathrm{MB}}\left(E_{t}\right)=\left(k_{B} T_{\text {trans }}\right)^{-2} E_{t} \exp \left[-E_{t} /\left(k_{B} T_{\text {trans }}\right)\right],
\end{aligned}
$$

where $r$ is a flight length for the photofragment. $P_{\mathrm{MB}}\left(E_{t}\right)$ is characterized by the average translational energy, $\left\langle E_{t}\right\rangle$ $=2 k_{B} T_{\text {trans }}$, where $k_{B}$ is the Boltzmann constant, and $T_{\text {trans }}$ is the translational temperature. Conversion from the energy distribution to the time-of-flight distribution was performed using the Jacobian listed by Zimmerman and Ho. ${ }^{21}$ The an-

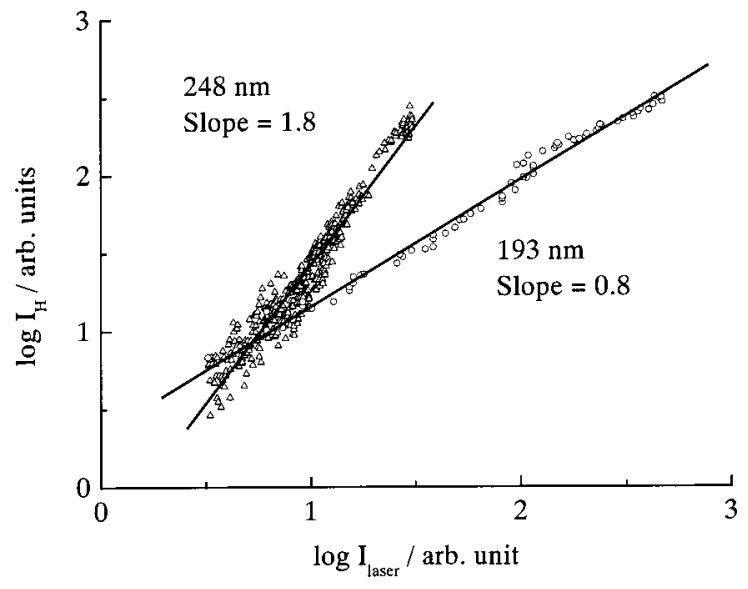

FIG. 3. Incident laser power dependencies of the $H$ signal intensities at 193 or $248 \mathrm{~nm}$, which were measured for the slow time-of-flight component B from amorphous ice at substrate temperature of $90 \mathrm{~K}$. The slopes are 0.8 \pm 0.1 for $193 \mathrm{~nm}$ and $1.6 \pm 0.2$ for $248 \mathrm{~nm}$.

gular distribution of the photofragments is set to be flat because of rough surfaces of amorphous ice films. The TOF spectrum consists of both a fast component $\mathrm{A}$ and a slow component $\mathrm{B}$, which are characterized by average translational energies of $2 k_{B} T_{\text {trans }}=0.39 \pm 0.04 \mathrm{eV}(2300 \pm 200 \mathrm{~K})$ and $0.02 \mathrm{eV}(120 \pm 20 \mathrm{~K})$, respectively. The slow component $\mathrm{B}$ is accommodated to the surface temperature prior to desorption.

As a function of laser intensity at $193 \mathrm{~nm}$ the REMPI intensity of the photofragment $\mathrm{H}$ atoms (B component) was measured at the peak TOF time. Incident laser power dependence of the signal intensity is $0.8 \pm 0.1$ as shown in Fig. 3, suggesting that $\mathrm{H}$ atoms are produced by a one-photon process. As a reference test, we performed $248 \mathrm{~nm}$ irradiation on an amorphous ice film at $90 \mathrm{~K}$. Incident laser power dependence of the $\mathrm{H}$ signal intensity was $1.6 \pm 0.2$. These results suggest that the photodissociation at $248 \mathrm{~nm}$ is induced by a two-photon process. In the gas phase photolysis at 240-250 $\mathrm{nm}$, the two-photon absorption to the third excited $\mathrm{C}\left({ }^{1} B_{1}\right)$ state of water monomer was reported by Zhang et al. ${ }^{22}$ The $\mathrm{C}\left({ }^{1} B_{1}\right)$ state is bound near the Franck-Condon region but is predissociated by the $B\left({ }^{1} A_{1}\right)$ and $A\left({ }^{1} B_{1}\right)$ states.

Figure 4 shows the substrate temperature dependence of TOF spectra of $\mathrm{H}$ atoms from the $193 \mathrm{~nm}$ photodissociation of $\mathrm{H}_{2} \mathrm{O}$ ice films, which are measured at the central wavelength of the REMPI Doppler profile. The $\mathrm{H}$ signal intensity decreased with increasing substrate temperatures from 110 to $140 \mathrm{~K}$. Water ice forms an amorphous structure at substrate temperatures below $130 \mathrm{~K}^{17,23}$ Above $130 \mathrm{~K}$, ice forms a cubic crystalline structure. ${ }^{24}$ Since the phase change of amorphous ice to crystalline ice occurs at $>120 \mathrm{~K},{ }^{17}$ the decrease of the $\mathrm{H}$ atom signal intensity is caused by loss of amorphous nature of the ice film surface. According to our theoretical calculation about the branched cluster $\left(\mathrm{H}_{2} \mathrm{O}\right)_{6+1}$, it can have the red-tailed UV photoabsorption.

The inset of Fig. 4 shows TOF spectra of D atoms from the $193 \mathrm{~nm}$ photodissociation of the $\mathrm{D}_{2} \mathrm{O}$ ice film with and without $\mathrm{H}_{2} \mathrm{O}$ overlayers. After $30 \mathrm{~L}$ exposure of $\mathrm{H}_{2} \mathrm{O}$ vapor over the amorphous $\mathrm{D}_{2} \mathrm{O}$ ice film at $90 \mathrm{~K}$, the fast TOF 


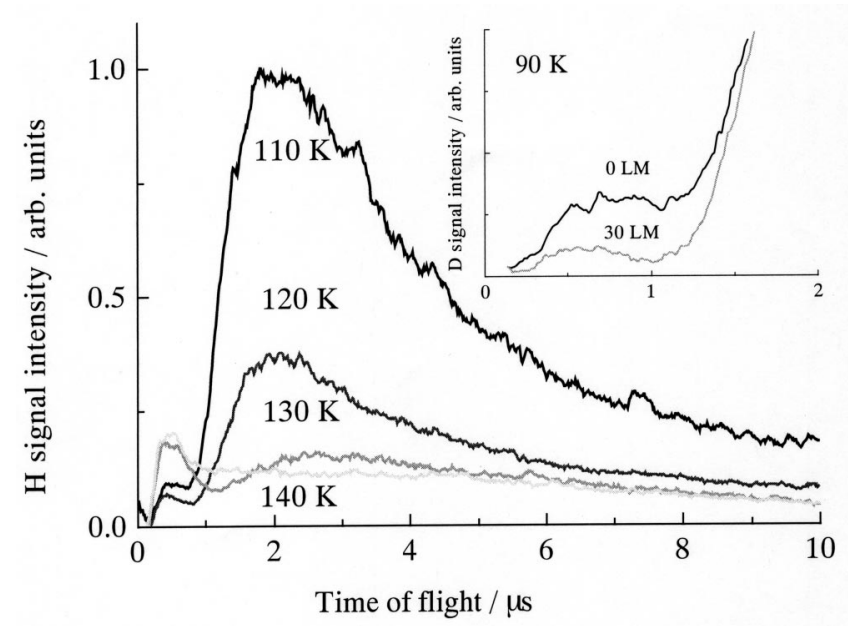

FIG. 4. Substrate temperature dependence of the time-of-flight (TOF) spectra of hydrogen atoms from the $193 \mathrm{~nm}$ photodissociation of ice. $\mathrm{H}_{2} \mathrm{O}$ was first deposited on a substrate at $90 \mathrm{~K}$, and then the substrate was heated stepwisely to the indicated (annealing) temperatures. The inset shows $\mathrm{H}_{2} \mathrm{O}$ coverage dependence on the fast time-of-flight component of D atoms from the $193 \mathrm{~nm}$ photodissociation of amorphous $\mathrm{D}_{2} \mathrm{O}$ ice at $90 \mathrm{~K}$. TOF spectra of $\mathrm{D}$ atoms were measured from $\mathrm{D}_{2} \mathrm{O}$ ice, (a) without exposure of the overlayer $\mathrm{H}_{2} \mathrm{O}$, and (b) with the overlayer $\mathrm{H}_{2} \mathrm{O}$ exposed for $30 \mathrm{~L}$. These TOF spectra are not averaged over the entire Doppler profile of the REMPI spectrum of the $\mathrm{H}$ atom, but the REMPI wavelength is fixed at the center wavelength of the Doppler profile.

component $\mathrm{A}$ of the $\mathrm{D}$ atoms disappeared, while the slow component $\mathrm{B}$ was not so affected at this exposure. These results indicate that the fast component $\mathrm{A}$ comes from the topmost $\mathrm{D}_{2} \mathrm{O}$ layer of the ice film. The translational temperatures of the A and B components shown in Fig. 2 are consistent with this assumption, that is, $\mathrm{H}$ atoms from the topmost water molecules have a kinetic energy corresponding to $T_{\text {trans }}=2300 \pm 200 \mathrm{~K}$. The $\mathrm{H}$ atoms of the B component have $T_{\text {trans }}=120 \pm 20 \mathrm{~K}$ that is close to the substrate temperature of $90-130 \mathrm{~K}$. The slow component B is accommodated to the surface temperature prior to desorption. Kimmel et al. show for amorphous ice films that (a) the porosity decreases with the annealing temperature (90-130 K) and (b) the porosity stays nearly constant above $130 \mathrm{~K}^{18}$ In the present experiment, the relative ratios of the $\mathrm{B}$ component to the $\mathrm{A}$ component first decrease, and then stay constant with the substrate (annealing) temperature (Fig. 4). Thus, the B component could come partly from water molecules in the micropores of the ice film.

We have also measured the TOF spectra from the amorphous ice films prepared at three different ice growth temperatures $(90,100$, and $110 \mathrm{~K})$. In this case water vapor was deposited at the growth substrate temperature and the prepared film was photodissociated at the growth substrate temperature. The intensity ratio of the $\mathrm{B}$ component over the A component is smaller than the ratio observed for the ice film that was prepared at $90 \mathrm{~K}$ and then annealed to the same substrate temperature. According to Kimmel et al. ${ }^{18}$ the porosity is low for the ice films prepared at growth temperatures above $90 \mathrm{~K}$. Thus, the origin of the B component is partly due to the photodissociation of the surface water molecules in the micropores. Since the temperature change in- duces not only the porosity change of the ice surface but also L- and D-defect concentration, etc. we need further experiments to confirm the origins of the temperature dependence observed in the TOF spectra.

\section{COMPARISON WITH PREVIOUS WORKS}

Several experimental studies on photodissociation of water adsorbed on cold surfaces were reported. ${ }^{25-28}$ Wolf et al. performed UV irradiation of an $\mathrm{H}_{2} \mathrm{O}$ bilayer adsorbed on $\mathrm{Pd}(111)$ at $95 \mathrm{~K}$. For 6.4 or $5.0 \mathrm{eV}$ irradiation, they found molecular desorption as well as dissociation of adsorbed molecules. ${ }^{26}$ Both processes are due to electron transfer from the metal substrate to the layered water molecules and not related to direct photoabsorption process of the ice film. Nishi et al. reported a very weak signal of $\mathrm{H}$ atom from the $193 \mathrm{~nm}$ photodissociation of pure water ice adsorbed on the quartz plate with a signal to noise ratio of $\sim 3$ only when the laser beam was so strongly focused $\left(0.5 \mathrm{~J} / \mathrm{cm}^{2}\right)$ that twophoton excitation of $\mathrm{H}_{2} \mathrm{O}$ molecules occurred. ${ }^{28}$ In the present experiment, two-photon dissociation occurred at 248 $\mathrm{nm}$ with laser intensity of $2 \mathrm{~mJ} \mathrm{~cm}^{-2}$, while the one-photon dissociation was observed at $193 \mathrm{~nm}$ and $0.5 \mathrm{~mJ} \mathrm{~cm}^{-2}$. Because their laser intensity was stronger by over two orders of magnitude than our laser intensity, the one-photon dissociation process was smeared out by the two-photon process in their experiment.

About the dissociation threshold wavelength, Kimmel and Orlando measured D atoms from the electron-stimulated dissociation of amorphous $\mathrm{D}_{2} \mathrm{O}$ ice adsorbed on $\mathrm{Pt}(111)$ at $\sim 90 \mathrm{~K} .{ }^{29}$ They reported a low energy threshold for $\mathrm{D}$ atom production is $6-7 \mathrm{eV}$. There exists the dissociative electronic state near $200 \mathrm{~nm}$. Their TOF spectra for D atoms consist of two components; one is ejected directly from the surface without interacting to surrounding molecules, and the other is accommodated to the surface temperature prior to desorption. These results are in good agreement with our TOF results. It is likely that the same electronic excitation and the dynamics occur in the photo- and electron bombardment dissociation.

\section{ATMOSPHERIC IMPLICATIONS}

The water vapor mixing ratio in the stratosphere and in the mesosphere of the Earth is maintained to be about 1-10 ppmv. Vardavas et al. have examined the role of $\mathrm{H}_{2} \mathrm{O}$ photodissociation on ozone concentration in the upper atmosphere with emphasis on the region between 70 and $95 \mathrm{~km}$ altitude, where water vapor photodissociation by the solar Lyman- $\alpha$ line is considered to be the dominant source of $\mathrm{H}$ atoms that initiate the $\mathrm{HO} x$ cycle to decrease the $\mathrm{O}_{3}$ mixing ratio. ${ }^{30}$ Vertical ozone profiles obtained by $\mathrm{HALOE}^{31}$ indicate that there is a deep minimum generated near the mesosphere at about $80 \mathrm{~km}$. The depth of the minimum mixing ratio of $\mathrm{O}_{3}$ is below 0.1 ppmv. Vertical ozone profiles and the $\mathrm{H}_{2} \mathrm{O}$ volume mixing ratios given by the ATMOS observations $^{32}$ and the UARA/ISAMS observations ${ }^{33}$ show a strong correlation between them. Those mixing ratios start becoming low at about $80 \mathrm{~km}$. Therefore, the mesopause 
ozone deep minimum is produced by the rapid destruction of water vapor by the solar Lyman- $\alpha$ line, and hence increase of $\mathrm{HO} x$ at altitudes between 80 and $85 \mathrm{~km}$.

In the low temperature regions of the Earth's atmosphere, water molecules will cluster together to form ice particles that become visible when they have grown to about 50 $\mathrm{nm}$ in radius. ${ }^{34-37}$ Noctilucent clouds (NLCs) are small water-ice particles, generated in the extremely cold (120$140 \mathrm{~K}$ ) mesopause region near $88 \mathrm{~km}$. Their most observable manifestation as thin $(1-3 \mathrm{~km})$ layers near $83 \mathrm{~km}$ is thought to be due to sedimentation downward from their height of origin, and growth by acquisition of water vapor in the denser regions. Lidar observations of ice crystals associated with NLCs have shown that a maximum column density is $10^{13} \mathrm{~cm}^{-2}$ at a radius of $0.02 \mu \mathrm{m} .{ }^{38}$ About atmospheric implication of the present results, we have estimated the relative contribution of the ice particle photodissociation to the hydrogen atom formation near the high-latitude mesopause region, comparing with that of water vapor photodissociation,

$$
H_{i}=\int d \lambda \sigma_{i}(\lambda) P_{i}(\lambda) \phi_{i}(\lambda) C_{i},
$$

where $H_{i}$ denotes the amount of $\mathrm{H}$ atoms produced from ice and vapor photolysis, $\sigma(\lambda)$ absorption cross section at wavelength $\lambda$, and $P(\lambda)$ is the solar flux. ${ }^{39}$ Water vapor is photodissociated at the Lyman- $\alpha$ line. The photon flux for vapor is set to $P_{\text {vapor }}(121.6 \mathrm{~nm})=3.6 \times 10^{11}$ photon $\mathrm{cm}^{-2} \mathrm{~s}^{-1}$, which is the flux at solar minimum. ${ }^{40}$ The photon flux for ice $P_{\text {ice }}(\lambda)$ will be discussed below. Since the absolute product quantum yield for the $\mathrm{H}$ atom production could not be measured in the present experiment, the yield is estimated as follows. The photodissociation quantum yield $\phi_{\text {vapor }}$ for water vapor is unity. $\phi_{\text {ice }}$ for ice could be larger than 0.04 that is taken from the reported yield (0.02) of hydrogen molecules from the bulk water ice photolysis in the vacuum $\mathrm{UV}^{41}$ It is smaller than unity since the surface water molecules that are hydrogen-bonding to the bulk ice surface are photodissociated. Hence, it would be reasonable to assume that $\phi_{\text {ice }}$ is 0.1 . The average concentration $\left\langle C_{\text {vapor }}\right\rangle=3.9 \times 10^{9} \mathrm{~cm}^{-3}$ of water vapor is taken from the reported mixing ratios $(5-10$ ppmV), ${ }^{30,37}$ atmospheric temperatures $(130-150 \mathrm{~K})$ and pressure $(0.01 \mathrm{mb})$ at a corresponding altitude of $80 \mathrm{~km} .{ }^{42}$ For NLC, the reported maximum column density of $10^{13} \mathrm{~cm}^{-2}$ and radius of $0.02 \mu \mathrm{m}$ give effective spherical surface areas that can be irradiated by the solar radiation. ${ }^{38}$ NLC particles have been shown to be nonspherical by recent polarization measurements and the surface of these particles is unlikely to be smooth. ${ }^{43}$ The measured surface area of water ice films formed from the vapor phase at temperatures relevant to NLCs have surface areas up to 500 times larger than the geometric surface area of the substrate. ${ }^{44}$ Murray and Plane, therefore, assumed that $A<5 \times 10^{-5} \mathrm{~cm}^{2}$, where $A$ is the volumetric surface area (total aerosol surface area per unit volume of atmosphere). ${ }^{45}$ Here we assume that the surface is uniformly covered by the hydrogen-bonding water molecules that have the red-tailed photoabsorption at 190$230 \mathrm{~nm}$. Using the lattice constant for a crystalline ice surface, we calculated the number of the hydrogen-bonding molecules that can absorb the solar radiation; $C_{\text {ice }}=2.5$ $\times 10^{10}$ molecule $\mathrm{cm}^{-3}$. In this calculation we assume that all $\mathrm{H}$ atoms pointing toward vacuum from the ice crystalline lattice are hydrogen-bonding to the $\mathrm{O}$ atoms of hydrogenbond acceptor water molecules, which are the three hydrogen atoms pointing upward in Fig. 1. The hydrogen-bond donor water molecule absorbs UV light at 190-230 nm. The absorption cross section of the hydrogen-bond donor water molecule of the ice surface, $\left\langle\sigma_{\text {ice }}(190-230 \mathrm{~nm})\right\rangle=1.6$ $\times 10^{-20} \mathrm{~cm}^{2}$, is taken from the dimer absorption cross section calculated by Harvey et al. ${ }^{15}$ The absorption cross section of water vapor, $\sigma_{\text {vapor }} 121.6(\mathrm{~nm})=5.4 \times 10^{-18} \mathrm{~cm}^{2}$. The photon flux for ice $P_{\text {ice }}(\lambda)$ is effective in the region of $\lambda=190-230 \mathrm{~nm}$, which is $1 \times 10^{14}$ photon $\mathrm{cm}^{-2} \mathrm{~s}^{-1}$. Using these parameters, the ratio of $H_{\text {ice }} / H_{\text {vapor }}$ is estimated to be $<0.5$, which indicates that the photodissociation of NLCs cannot be neglected in terms of the HOx cycle to ozone depletion near the high-latitude mesopause. This odd hydrogen reaction can also be applied to explain the loss of $\mathrm{O}$ atoms at $80 \mathrm{~km}$ altitude. ${ }^{45}$

\section{ACKNOWLEDGMENTS}

The authors thank Professor R. Bersohn of Columbia University for stimulating discussions and Dr. B. J. Murray and Professor. J.M.C. Plane of the University of East Anglia for sending us their preprint. This work is supported by a Grant-in-Aid in the priority research field "Radical Chain Reactions" from the Ministry of Education, Japan.

${ }^{1}$ R. Schinke, Reaction Dynamics: Spectroscopy and Fragmentation of Small Polyatomic Molecules (Cambridge University Press, Cambridge, 1995).

${ }^{2}$ H. Okabe, Photochemistry of Small Molecules (Wiley, New York, 1978).

${ }^{3}$ C-Y. Chung, E. P. Chew, B-M. Chen, M. Bahou, and Y-P. Lee, Nucl. Instrum. Methods Phys. Res. A 467, 1572 (2001).

${ }^{4}$ O. Dutuit, A. Tabche-Fouhaile, I. Nenner, H. Frohlich, and P. M. Guyon, J. Chem. Phys. 83, 584 (1985).

${ }^{5}$ D. F. Plusquellic, O. Votava, and D. J. Nesbitt, J. Chem. Phys. 107, 6123 (1997).

${ }^{6}$ M. Seki, K. Kobayashi, and J. Nakahara, J. Chem. Phys. 50, 2643 (1981).

${ }^{7}$ K. Kobayashi, J. Phys. Chem. 87, 4317 (1983).

${ }^{8}$ K. Dressler and O. Schnepp, J. Chem. Phys. 33, 270 (1960).

${ }^{9}$ A. P. Minton, J. Phys. Chem. 75, 1162 (1971).

${ }^{10}$ When cyclic $\left(\mathrm{H}_{2} \mathrm{O}\right)_{7}$ is optimized, it forms a double ring structure consisting of a 3-membered ring plus a 4-membered ring.

${ }^{11}$ M. J. Frisch, G. W. Trucks, H. B. Schlegel et al., Ab initio MO program, GAUSSIAN 98, Revision A.5, Gaussian, Inc., Pittsburgh, PA, 1998.

${ }^{12}$ M. A. Zondlo, T. B. Onasch, M. S. Warshawsky, M. A. Tolbert, G. Mallick, P. Arentz, and M. S. Robinson, J. Phys. Chem. B 101, 10887 (1997).

${ }^{13}$ B. N. Hale, J. Kiefer, and C. A. Ward, J. Chem. Phys. 75, 1991 (1981).

${ }^{14}$ M. J. Frisch, I. N. Ragazos, M. A. Robb, and H. B. Schlegel, Chem. Phys. Lett. 189, 524 (1992).

${ }^{15}$ J. N. Harvey, J. O. Jung, and R. B. Gerber, J. Chem. Phys. 109, 8747 (1998).

${ }^{16}$ A. Yabushita, Y. Inoue, T. Senga, M. Kawasaki, and S. Sato, J. Phys. Chem. B 106, 3151 (2002).

${ }^{17}$ S. Sato, D. Yamaguchi, K. Nakagawa, Y. Inoue, A. Yabushita, and M. Kawasaki, Langmuir 16, 9533 (2000).

${ }^{18}$ G. A. Kimmel, K. P. Stevenson, Z. Dohnálek, R. S. Smith, and B. D. Kay, J. Chem. Phys. 114, 5284 (2001).

${ }^{19}$ D. E. Brown, S. M. George, C. Huang, E. K. L. Wong, K. B. Rider, R. S. Smith, and B. D. Kay, J. Phys. Chem. 100, 4988 (1996).

${ }^{20}$ B. Rowland and J. P. Devlin, J. Chem. Phys. 94, 812 (1991).

${ }^{21}$ F. M. Zimmermann and W. Ho, Surf. Sci. Rep. 22, 127 (1995). 
${ }^{22}$ J. Z. Zhang, E. H. Abramson, and D. G. Imre, J. Chem. Phys. 95, 6536 (1991).

${ }^{23}$ W. Hagen, A. G. G. M. Tielens, and J. M. Greenberg, Chem. Phys. 56, 367 (1981).

${ }^{24}$ D. Eisenberg and W. Kauzmann, The Structure and Properties of Water (Oxford University Press, New York, 1969).

${ }^{25}$ S. R. Baggott, K. W. Kolasinski, Luís M. A. Perdigão, M. A. Luis, D. Riedel, Q. Guo, and R. E. Palmer, J. Chem. Phys. 117, 6667 (2002).

${ }^{26}$ M. Wolff, S. Nettesheim, J. M. White, E. Hasselbrink, and G. Ertl, J. Chem. Phys. 94, 4610 (1991).

${ }^{27}$ P. A. Thiel and T. E. Madey, Surf. Sci. Rep. 7, 211 (1987).

${ }^{28}$ N. Nishi, H. Shinohara, and T. Okuyama, J. Chem. Phys. 80, 3898 (1984).

${ }^{29}$ G. A. Kimmel and T. M. Orlando, Phys. Rev. Lett. 75, 2606 (1995).

${ }^{30}$ I. M. Vardavas, J. H. Carver, and F. W. Taylor, Ann. Geophys. 16, 189 (1998).

${ }^{31}$ Halogen Occultation Experiment launched on UARS, in September 1991 as part of the Mission to Planet Earth, MTPE, Program.

${ }^{32}$ M. R. Gunson, C. B. Farmer, N. R. Norton, R. Zander, C. P. Rinsland, J. H. Shaw, and B. C. Gao, J. Geophys. Res. 95, 13867 (1990).

${ }^{33}$ M. Goss-Custard, J. J. Remedios, A. Lambert et al., J. Geophys. Res. 101, 9907 (1996)
${ }^{34}$ G. E. Thomas and C. P. McKay, Planet. Space Sci. 33, 1209 (1985).

${ }^{35}$ G. von Cossart, J. Fiedler, and U. von Zahn, Geophys. Res. Lett. 26, 1513 (1999).

${ }^{36}$ M. Alpers, M. Gerding, J. Hoffner, and U. von Zahn, J. Geophys. Res. 105, 12235 (2000).

${ }^{37}$ P. J. Espy and H. Jutt, J. Atmos. Sol.-Terr. Phys. 64, 1823 (2002).

${ }^{38}$ L. Thomas, A. K. P. Marsh, D. P. Wareing, and M. A. Hassan, Geophys. Res. Lett. 21, 385 (1994).

${ }^{39}$ G. P. Brasseur, J. J. Orlando, and G. S. Tyndall, Atmospheric Chemistry and Global Change (Oxford University Press, New York, 1999).

${ }^{40}$ T. N. Woods, W. K. Tobiska, G. J. Rottman, and J. R. Worden, J. Geophys. Res. 105, 27195 (2000).

${ }^{41}$ N. Watanabe, T. Horii, and A. Kouchi, Astrophys. J. 541, 772 (2000).

${ }^{42}$ J. M. Wallace and P. V. Hobbs, Atmospheric Science (Academic, New York, 1977).

${ }^{43}$ G. Baumgarten, K. H. Fricke, and G. T. von Cossart, Geophys. Res. Lett. 29, 1630 (2002)

${ }^{44}$ F. J. Lübken, K. H. Fricke, and M. Langer, J. Geophys. Res. 101, 9489 (1996).

${ }^{45}$ B. J. Murray and J. M. C. Plane, Adv. Space Res. 31, 2075 (2003). 